Historic, Archive Document

Do not assume content reflects current scientific knowledge, policies, or practices. 



\section{THE IDEAL EVERGREEN}
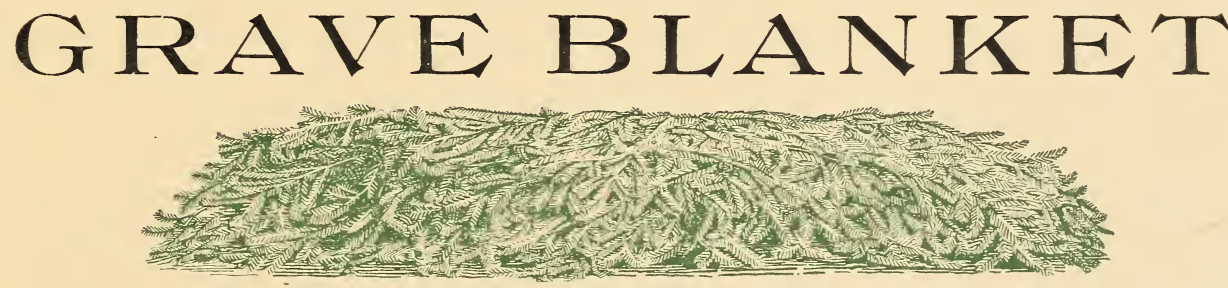

Nothing can approach it for beauty as a winter covering for graves. Our special method of weaving gives it the rich mound effect so greatly admired. The Ideal Blanket is manufactured 80 by 30 inches. Smaller sizes to order.

Prepared Evergreens, Grasses, Rose Mounted Cones, Imperial Statise, Miniature Cat-tails, Ideal Sprays.

\section{ROCKY MOUNTAIN EVERGREEN COMPANY}


